\title{
Food and wine tourism in post-war Lebanon
}

\author{
L. N. Milich \\ Department of Recreation, Parks, and Tourism Administration, \\ California Polytechnic State University, USA
}

\begin{abstract}
Tourism has played a major role in Lebanon since its peak period of 1930-1974; sometimes subsiding as a result of war and conflict, but always rebounding at least to some extent. Lebanon's touristic appeal includes its geographic location between the East and the West, its varied landscape (beaches and mountains), its hospitable and diverse population, and its well loved cuisine. The purpose of this study was to develop an understanding of the nature of regional and community based initiatives within the interrelated sectors of food and wine tourism in postwar Lebanon. Data was collected in January 2011 through personal interviews with experts in the field. Findings revealed a need for greater support of the food and wine industry, as it has proven to be a sustainable alternative to traditional touristic development strategies. The researcher found that initiatives such as those referred to in this study are beneficial to the country as a whole and to the strengthening of the traditional tourism sector partly because of the opportunity they provide for diversification. Establishing and promoting a strong network of sustainable minded food and wine initiatives with a similar set of goals and objectives across the country will help spread the benefits of tourism to areas and groups typically not reached by its financial and cultural benefits. This will also lessen the strain on currently marketed, overly concentrated areas and will create for a more sustainable, more multidimensional, more interesting, and less destructible/vulnerable industry on the whole.

Keywords: wine tourism, Lebanon, food tourism, culinary tourism, communitybased initiatives.
\end{abstract}

\section{Introduction}

Prior to a 17-year civil war that broke out in 1975, Lebanon was a prime tourist destination, and was known internationally as the "Switzerland of the Middle 
East" (Kanso [1]). In 1974, Lebanon welcomed roughly 1.5 million visitors (Kanso [1]). During the war, tourism practically came to a halt, and the country's economy suffered immensely. Infrastructure was destroyed, safety could not be guaranteed, and services necessary for travel were virtually nonexistent. When the Civil War finally ended in 1991, and once Israel lifted its naval ban in South Lebanon in 2001, the country demonstrated notable resilience as it began to rebuild. A particular emphasis was placed on efforts to promote growth in tourism (Citrinot [2]). Although a war-torn image from international markets made tourism a tough sell initially, the government provided incentives for domestic rebuilding in the hospitality and services industry (Ladki and Dah [3]), and within a number of years, tourism had increased considerably. Tragically, violence broke out again in 2006, between the Israel Defense Forces (IDF) and Hezbollah. Although the 36-day war was not nearly as long as the civil war of the 1970s and 80s, damage was significant (Ladki et al. [4]). Lebanon had to rebuild once again. During this most recent restructuring, new ideas emerged at the community level, and private enterprises such as farmer's markets, craft markets, and traditional food production appeared (El Tayeb staff [5]). These projects took less time to mobilize than larger government funded projects, and provided stakeholders with a sense of ownership as well as allowance for creativity. The purpose of this study was to develop an understanding of the nature of these regional and community based initiatives within the context of food and wine tourism in post-war Lebanon.

Tourism in modern day Lebanon can be broken down into the following phases: pre-Civil War (1930-1974), Civil War (1975-1991), the interim between the end of the Civil War and the Israeli invasion of Beirut (1991-2006), and post2006. This study will focus primarily on the trends that have taken place during the two post war phases (1991-July 2006, and August 2006 to the present).

While post war "recovery" always meant first and foremost a national agenda of rebuilding essential physical infrastructure such as the airport, housing developments, roads, ports, schools, etc. (Citrinot [2]), it also often involved a focus on two sectors that have always been critical to the national character of Lebanon: food and tourism. To a lesser extent, and particularly in recent years, wine tourism has also played a role in redevelopment (Blomfield and Short [6]).

The period of reconstruction since the latest conflict, the July 2006 war with Israel, has been characterized by a growing segment of small private businesses and community initiatives (Lebanon's boutique [7], El Tayeb staff [5]), following suit with global trends that imply an interest in personalized tourism experiences and "genuine products" (Jahn and Thomson [8]). The Lebanese people have noted the international appeal of their culinary traditions and agricultural endowments, and as a result they are emphasizing growth in this market (Fabricant [9], Lebanon's boutique [7]). Food and wine in Lebanon can now be seen as a main attraction for potential visitors (Fabricant [9]). It also provides an opportunity for people of various backgrounds to benefit from tourism, where they may not have been able to benefit before. For example, in previous reconstruction phases, farmers and residents of rural villages outside of the main tourist hub of Beirut may not have seen a link between the country's 
heavy investments in tourism and their own needs (Lebanon prepares [10]). Now, with the growth of community oriented initiatives such as Souk el Tayeb and Mymoune, people from all over the country, often with no previous experience in this sector, are able to benefit from tourism.

\section{Results}

The purpose of this study was to develop an understanding of the nature of regional and community based initiatives within the interrelated sectors of food and wine tourism in post-war Lebanon. The researcher interviewed experts in the field of food and wine tourism in Lebanon. Candidates were selected based on their involvement in and knowledge of food and/or wine tourism in Lebanon. Data collection was finalized once the researcher had reached maximum feasible saturation in interview content from as many experts as possible (i.e. once subjects began to repeat recommendations for other experts in the field).

\subsection{Subject characteristics}

Stakeholders in the Lebanese food and wine industry are wide-ranging and include Lebanese expatriates displaced by the war who've returned to revive the local economy and lifestyle, various leaders in the wine industry, Lebanese residents in Beirut (primarily as consumers, but also employees and project developers), residents of the various regions and villages of the country (primarily as local employees and "hosts" of tourism activities), authors and bloggers on Lebanese cuisine and culture, hosts of culinary tours of the region, and a wine expert who organizes local wine tours and offers wine education courses. Lebanese tourism appears to consist primarily of Arabs from the Middle East who are less frequently deterred by regional political tensions than are their Western counterparts. Visitation from members of the Lebanese Diaspora also makes up a significant segment of tourism in the country, as does "internal" tourism (for example, people from Beirut interested in learning about their culinary heritage traveling to a Food and Feast event in a village, or attending a wine tasting event in the Bekaa Valley). Participants in this study were based in Beirut on the central coast, in the Bekaa Valley, in a village east of Beirut near the Lebanon Mountains, and outside of Lebanon.

\subsection{Industry trends and characteristics}

Food tourism appears to be a somewhat less organized and less established sector than is wine tourism, though almost all subjects commented positively on the potential for growth in this area. Numerous independent enterprises with a focus on agriculture and food exist, though their role as related to tourism is not typically well defined; in these cases the focus tends to be on production, sales, and the organization's respective goals and objectives, with tourism as an afterthought. 


\subsection{Stakeholder motivations}

Subjects were asked, "How and why did you get involved in this role/sector?" as well as "What are your goals and objectives?" Some common objectives that emerged include national unification, preservation of Lebanese heritage and tradition, provision of high quality food and wine products/packages, promotion of peace and stability through various initiatives, and creating "a good image of a country undermined by political tensions and wars." One winery owner stated the primary reason for founding their organization as to "help bring back the population who had fled years before to escape...the war" and noted that they have since "kept the needs of the community of primary importance." Though certainly financial sustainability is an elemental concern for all of the businesses referred to in this study, at least one altruistic motivation was mentioned in all responses. In most cases the needs of the community and/or Lebanon as a whole was noted as the primary reason for involvement in food and wine tourism initiatives. A strong sense of pride in the quality of regionally available agricultural products, and a devotion to the Lebanese cultural identity was evident in all responses.

\subsection{Methods to promote growth in the industry}

Subjects were asked, "How do you promote your business or project?" The most common response was "word of mouth." Representatives of the large, long established wineries also noted specific marketing and promotional strategies such as web-based publicity, billboards, advertisements, participation in international wine fairs, and export specific publicity as managed by international partners and distributors. Some of the initiatives were non-profit and/or simply didn't allocate a significant budget to marketing/PR. In these cases, funds were simply not available to spend on paid advertisements etc., and other aspects of the business/project were considered a higher priority in regards to the allocation of what funds were available. Subjects were usually also asked if they received any governmental assistance or aid from NGO's. None of those asked mentioned that they'd received financial assistance from external groups or from the government. Articles and written press were acknowledged as other important means for promoting growth in the industry. One winery representative noted that "tourism is a key factor in developing our business, and showing a better image of Lebanon." Finally, all subjects were clearly dedicated to the efficiency and betterment of their respective organizations, thus portraying an attitude which would lend to the growth of the industry as a whole.

\subsection{Stakeholder's expectations}

Subjects were asked "Do you believe that your business/project is helping the Lebanese community?" and "If so, in what ways?" Since all subjects mentioned that at least one of their objectives was to help the Lebanese community (or local community) in some way, this question is relative to how the business/project has progressed in achieving its own operational goals and expectations. 
Employment is one way in which the businesses involved in this study have contributed to economic sustainability in the region, employing up to 110 individuals at the largest winery. Another contribution frequently noted by subjects was that of improving Lebanon's image. The majority of participants mentioned that in some way(s) their work had helped to improve the image of the country and has spread awareness of the true character and quality of Lebanese food and culture (both among Lebanese who have lost touch with their traditions, and internationally). A higher concern than spreading the word internationally, however, seemed to be the objective of building a stronger sense of unity and pride within Lebanon. Stakeholders appear to be reaching their expectations in regards to this.

\subsection{Sustainability and benefits of food and wine tourism}

The overwhelming response to the question of "Is food and wine tourism a viable option for economic and cultural diversification in Lebanon?" was that yes, tourism is an important part of the economy and it should be supported. However, its success is dependent on stability in the region. The general opinion among subjects was that tourism (and specifically food and wine tourism) can only be successful, and its benefits fully reaped, so long as longstanding political tensions are absolved and peace is secured. Still, the potential for growth in the area of food and wine tourism was widely noted.

Comments regarding the potential for wine tourism in Lebanon were very positive. Observations made by some of the leading experts in the industry included: "Wine tourism...has enormous potential," and "[the wine industry] is booming, not only growing." Another individual remarked that "certainly in Lebanon [food and wine tourism] is sustainable because of the food-there is a real gastronomy, so people are really interested in the food and it is a way for people to re-visit a country for instance. And there are enough wineries to make a viable itinerary for tourists." Many of these initiatives have indicated specific measures taken, and a primary interest in managing their operations in ways that will be sustainable. Reasons for a focus on sustainable practices include a love and appreciation for the land, the cuisine, the people of Lebanon, and a desire to see the long term continuation of these things.

Specific ways in which participants have demonstrated sustainable and beneficial practices include: local employment and economic stimulation, "helping the customers know more about their traditions and legacy," "establishing a network of all the stakeholders in the environment, "development...gathering people who believe in change to work together," "[making] accessible to the general public knowledge on food traditions," "[giving] a good image of a country undermined by political tensions and wars," "[supporting] small scale farmers and producers," and "building a national bond/identity."

The results of this study indicate a need for change and adaptation in the Lebanese tourism industry, as well as recognition of the importance of food and wine related initiatives in relation to tourism activity and visitor incentives. 


\section{Discussions and conclusions}

The timeliness of this study is such that it coincides with an opportunity for change and renewed energy in the food and wine tourism industry in Lebanon. The global movement toward sustainability has picked up speed in recent years, and Lebanon has the assets to benefit from this trend both in terms of touristic desirability and national development. This is a time in which the country would greatly benefit from growth and partnership among initiatives which have proven their ability to inspire national unity and strength among Lebanon's diverse population.

\subsection{Summary of results}

Following an analysis of the data collected for this study, the researcher found that some primary objectives for food and wine tourism initiatives in the country included promoting pride and unity among Lebanon's diverse population, establishing a more positive image of Lebanon as a destination, and endorsing the preservation of Lebanon's rich heritage and traditions. The study also found that there was a consensus among subjects in the belief that tourism development (and specifically food and wine tourism) holds the potential for significant benefits, though this potential can only be fully attained when there is security and peace in the region. Political tension and instability were named as the primary hindrances to desired growth in food and wine tourism, though subjects also provided some feasible recommendations for strengthening the industry in spite of these obstacles.

\subsection{Discussion}

The results from this study showed both consistency and inconsistency with previous research, though as far as the researcher is aware there has not been extensive research conducted on this particular topic before, so correlations between such studies should be viewed as somewhat limited in scope. The results from this study confirmed what was noted in prior research on tourism clientele; tourists in Lebanon consist primarily of Arabs from neighboring countries, internal tourists, and Lebanese expatriates. Travelers from Europe and America appear to be the next most present, although potential visitors from these regions seem to be more strongly affected by regional tensions (deterred) than other groups. The majority of clientele served by participants in this study were Lebanese; in most cases foreign tourism made up a lesser percentage of activity than did domestic tourism. Some groups reached out to a wider audience by participating in international food and/or wine festivals, and in some cases by participating in online sales or export of their products.

Also consistent with previous research was the finding that there is a strong potential for growth in the Lebanese tourism industry. Lebanon's primary attractions have been noted in previous research as its geographical diversity 
unique to the region, its agricultural resources and culinary traditions, as well as a rich historical heritage. These results were confirmed by this study; subjects often mentioned these assets as reasons for the potential for growth in Lebanese tourism. However, as previously noted, subjects in this study almost always referred to the potential for such growth as dependent on the conditions peace and stability.

According to prior research, "The tourism sector is the first to suffer from violence and war, and the first to benefit from peace" (Aboukhalil [11]). Similarly, one subject noted that "Tourism is a major support to the economy here, and unfortunately the first thing to suffer in times of political strife."

Results from this study have shown that food and wine tourism initiatives are relatively well established in Lebanon, though the "sector" (greater cohesion should be established before this segment can truly be considered a legitimate "sector" or "industry") could benefit from strengthened unity and partnership. This study has also shown that food and wine initiatives range in size and character; from non-profit developmental projects to privately run, internationally represented businesses. Employment (as represented by participants in this study) ranges from 1 to 110 persons, although the impact of these initiatives is not limited to number of persons employed, as they all produce effects in other ways as well. Some examples of these impacts include leading groups on tours throughout the region (differing from prior, government sponsored projects that have been primarily concentrated in Beirut), educating Lebanese people about their culinary heritage and traditions, inspiring pride in the quality of local products, and introducing an international audience to Lebanese food, wine and culture through press-related work.

All subjects conveyed that tourism, and specifically food and wine tourism, holds the potential for significant and sustainable growth. All agreed that Lebanon's culinary and agricultural resources and traditions are unique facets of the national character that could be harnessed to promote regional unity as well as a marketable tourism destination.

\subsection{Conclusions}

The researcher concludes, based on this, that the nature of traditional tourism development should be altered so that it can occur in a way that is less costly and more closely connected with the food and wine industries (where they are not already conjoined). The researcher believes that this will create a more efficient, more sustainable channel for national growth. This adjustment will allow for greater flexibility in the tourism sector; by placing an emphasis on developmental projects related to food and wine (i.e.: initiatives that have proven their ability to survive internal strife and inconsistencies, as indicated by this study), the industry can better adapt to environmental changes. For example, if tourism development occurs with a sole focus on investment in costly infrastructure and tourism-specific, regionally-concentrated services, these efforts and expenses could potentially be lost in the event of war (as occurred in 
2006) or other unforeseen circumstances. Furthermore, the impact of this loss would be a significant burden to the many people solely involved in that sector in the case that tourism suddenly slowed or halted. Food and wine tourism initiatives on the other hand, have shown a greater ability to adapt to such environmental changes, and to rebound during times of peace (such initiatives rely on teams of people whom have demonstrated notable resiliency in the past, rather than on physical structures which can be easily destroyed).

These initiatives are better able to adapt to unpredictable situations because of their multidimensional nature. The beneficiaries of investment in the growth of food and wine tourism combined with an effort to alter the main features of traditional tourism as indicated above would include stakeholders in mainstream tourism (non-related to the food and wine sectors), stakeholders in agriculture and wine producing sectors (i.e. farmers, producers, and consumers), and anyone else interested in the long term sustainability of Lebanon's environmental, culinary, and cultural traditions/assets.

By cooperating with food and wine tourism initiatives, stakeholders in traditional tourism venues will benefit from increased diversification (strength through partnerships), and new opportunities to provide their customers with an optimally satisfactory experience. Previous literary research has shown that Lebanon's excellent cuisine and agricultural resources are draws for tourists. The results from this study support this; they have shown a consensus among experts in the field that Lebanon's agricultural products, wine, and culinary traditions are well worth preserving for reasons including their appeal to tourists.

Members of the food and wine sectors will benefit from this proposal in that they will generate greater support from other establishments in the country. For example, hotels will recommend an itinerary for guests based on established wine routes, and/or culinary tourism initiatives. They will dedicate time and effort to understanding the specific features which these various programs have to offer and will then be able to satisfy customers based on their specific interests. Hotels, tour companies etc. should work together with both small and large food and wine establishments from locations all over the country (rather than direct them solely to activities in Beirut, Baalbek, and other locations with a concentration in tourism). This will allow for a more unique travel experience to tourists, and will help to break down the problem of negative imagery by encouraging travelers to see the vastness of what the country has to offer. Satisfied travelers will then spread the word about the unique aspects of Lebanon as a destination through internet reviews, blogging, press, and/or word of mouth.

Food and wine tourism should be supported because it is a sustainable practice in theory, and largely in effect as it is currently occurring in Lebanon. All food and wine initiatives referred to in this study have indicated at least some interest in the betterment of the country as a whole, and/or of the local community (and in many cases these interests are regarded as a primary objective). The interest here is not simply rhetoric, as it is for some tourist destinations worldwide which have endeavored to take advantage of growing trends in "sustainable tourism" and "responsible travel." The participants in this study have outlined specific ways in which they have and do continue to support 
the local community. For example, when probed on the question of "How is your operation helping the local community?" one subject stated the following:

...Our influence? Well, it starts in the valley, which had thousands of $\mathrm{km}$ of stone terraces lying fallow. We began to plant vines, and very slowly, other families became more interested in restoring their own agricultural land...Locally, the knowledge that someone was working in the valley was a catalyst for others to farm again...We employ members of local families who then have the resources and will to stay in [the village] throughout the year, enrolling their children in local schools, and patronizing a variety of small businesses for 12 months rather than 3 or 4 months in the summer only...We are working towards a critical mass of vineyards planted across the valley to discourage wanton construction...Fourthly, a more recent facet of our work: pride. People [from this village] here in Lebanon and abroad are waking up to the realization that the vineyards they remember from childhood are producing again, and producing outstanding wines. Our work has become the hub of a wheel whose spokes extend in all directions around the world, and many people want to be a part of it.

The focus of this study has indicated one of the primary problems in tourism as a global industry; it's potential for inconsistency. While external factors affect all industries to some extent, tourism is particularly vulnerable to environmental changes. Thus, diversification and de-centralization is essential to an efficient tourism strategy, particularly in a place like Lebanon where political tensions frequently shake the region. In the past, tourism in this country has time and again made post-conflict comebacks, thanks in large part to the resiliency of the Lebanese people and in some cases to massive redevelopment projects (postCivil War Beirut). As one subject has noted, "One relies on Lebanese resiliency and their ability to manage..." Though the determination of the Lebanese people has often been regarded as a primary factor in touristic recovery following periods of extreme hardships, the researcher believes that a better strategy to relying on the population's impressive ability to survive tenuous times is that of equipping stakeholders in the industry with appropriate investment, support, and practical tools which will enable these individuals/organizations to reach their full potential.

The strategy of developing tourism through large, costly projects which focus on building structures without a corresponding investment in building a network of people has not proved appropriate for Lebanon. First and foremost, before tourists can be accommodated, the local people employed in the service sector must be properly accommodated (i.e. through training, education, support, opportunity and tools for sustained growth). Of course, adequate infrastructure is necessary and must be included in redevelopment/development strategies, but it should also be noted that while buildings are vulnerable to destruction and abandonment during times of conflict or neglect, a strong network of people and 
partnerships will survive, and may even deter conflict by fostering a solidifying sense of unity, community, and positive energy.

Food and wine tourism is a sustainable niche market that is unique in Lebanon, and which holds the potential for many benefits. It is a viable market segment which should be perceived as a legitimate contributor to the economy and well-being of Lebanon's past, present and future. The segment would be more likely to achieve this image once it has created firm partnerships and networks both between similar-minded initiatives, as well as between food/wine tourism initiatives and members of the traditional tourism industry (i.e. hotels, tour operators, travel publications). Initiatives such as those referred to in this study are beneficial to the country as a whole and to the strengthening of the traditional tourism sector partly because of the opportunity they provide for diversification. Establishing and promoting a strong network of sustainable minded food and wine initiatives with a similar set of goals and objectives across the country will help spread the benefits of tourism to areas and groups typically not reached by its financial and cultural benefits. This will also lessen the strain on currently marketed, overly concentrated areas and will create for a more sustainable, more multidimensional, more interesting, and less destructible/vulnerable industry on the whole.

\section{References}

[1] Kanso, A., Reinvigorating the "Switzerland of the Middle East": How the Lebanese government can use public relations to reposition the country as a premier tourism destination. Journal of Hospitality \& Leisure Marketing, 12(1/2), 135-156, 2005.

[2] Citrinot, L. Lebanon: Country reports, http://www.countryreports.org/, 2002.

[3] Ladki, S. M., and Dah, A. Challenges facing post-war tourism development: The case of Lebanon. Journal of International Hospitality, Leisure \& Tourism Management, 1(2), 35-43, 1997.

[4] Ladki, S. M., Atallah, H., Hamam, F., and Hariri, M. E. The summer 2006 Lebanese food crisis: A quality of life perspective. Journal of Foodservice Business Research, 11(1), 96-107, 2008.

[5] El Tayeb staff. 4 years of Souk el Tayeb. El Tayeb newsletter, p. 1-16, July 2008.

[6] Blomfield A., and Short R. Women rescue Lebanon's wine after fighting threatens to ruin harvest. The Telegraph, 24 August 2006. Retrieved from http://www.telegraph.co.uk/

[7] Lebanon's boutique hotel sector shows high potential for future growth. The Daily Star, 6 September 2010. Retrieved from http://www.thefreelibrary.com/

[8] Jahn, H., and Thomson, C. C. Developing Southern Mediterranean tourism: The interface between strategy and sustainability. In M. Buck and R. Conrady (Ed.), Trends and Issues in Global Tourism 2009 (pp. 137-153). Heidelberg, Germany: Springer, 2009. 
[9] Fabricant, F. Top chefs and restaurateurs are drawn to Beirut. The New York Times, 2010. Retrieved from http://www.nytimes.com/

[10] Lebanon prepares for summer tourist invasion. Ya Libnan, 3 April 2010. Retrieved from http://www.yalibnan.com/

[11] Aboukhalil, A. Going all out to promote business and tourism. The Daily Star, pp.1-2, 12 April 2002. 